\title{
Kajian Systematic Literature Review (SLR) Untuk Mengidentifikasi Dampak Terorisme, Layanan Konseling dan Terapi Trauma Pada Anak-Anak
}

\author{
Urotul Aliyah \\ Universitas Negeri Semarang \\ aliyah.thobroni@gmail.com \\ Mulawarman \\ Universitas Negeri Semarang \\ mulawarman@mail.unnes.ac.id
}

\begin{abstract}
The purpose of writing this article is to determine the impact of terrorism on children and adolescents who live in the area of terror. The method used is the method of systematic literature review (SLR). SLR is a method that identifies, evaluates, and interprets findings on a research topic to answer a predetermined research question. From planning, conducting and reporting it can be concluded that terrorism has had a traumatic impact on many people, especially children and adolescents. The impact of terrorism can be experienced by children and adolescents in those who live at the scene of terror and children and adolescents of families of terrorists who experience negative stigma from the community as a family of terrorists. Children and adolescents affected by terrorism experience crucial problems to be able to rise up and undergo their psychological development naturally and without the pressure of trauma so that they need certain counseling so that they get up and are optimistic about their life's journey and the next stages of development. The recommendation of this study is the need for counseling to take on the role of strategy as an effort to build positive attitudes of children in facing the next stage of life so that they can undergo and realize career development positively as is usual for children and other adolescents who are not affected by terrorism. Moreover, learning from many countries, the government as a state representative must continue to be encouraged to care and dare to build a strong willingness to form institutions and regulatory
\end{abstract}


frameworks for counseling services in many fields for increasingly diverse needs, especially the handling and prevention of trauma from the impact of terrorism.

Keywords: SLR, Trauma impact of Terrorism, Children's Counseling

\begin{abstract}
Abstrak
Tujuan artikel ini untuk mengungkap dampak terorisme terhadap anak dan remaja yang tinggal di lokasi terror maupun dampak tidak langsung dari terror yang disiarkan melalui media massa, serta menunjukkan layanan konseling dan terapi trauma dibutuhkan untuk memulihkan korban menjadi lebih baik. Metode yang digunakan adalah Systematic Literature Review (SLR). SLR merupakan metode yang mengidentifikasi, menilai, dan menginterpretasi temuan-temuan pada suatu topik penelitian untuk menjawab pertanyaan penelitian (research question) yang telah ditetapkan sebelumnya. Dari planning, conducting dan reporting dapat disimpulkan bahwa terorisme telah memberikan dampak traumatis kepada banyak orang khususnya anak dan remaja. Dampak terorisme dapat dialami anak dan remaja pada mereka yang tinggal di lokasi kejadian teror serta anak dan remaja dari keluarga pelaku terror yang mengalami stigma negatif dari masyarakat sebagai kelaurga teroris. Anak dan remaja terdampak terorisme mengalami persoalan krusial untuk dapat bangkit dan menjalani perkembangan psikologisnya secara wajar dan tanpa tekanan trauma sehingga membutuhkan konseling tertentu agar mereka bangkit dan optimis memandang perjalanan hidup dan tahapan perkembangan mereka berikutnya. Rekomendasi dari kajian ini ialah perlunya konseling mengambil peran strategi sebagai upaya membangun sikap positif anak dalam menghadapi tahapan hidup berikutnya agar mereka dapat menjalani dan mewujudkan perkembangan karir secara positif sebagaimana lazimnya anak dan remaja lain yang tidak terdampak terorisme. Terlebih lagi, belajar dari banyak negara, pemerintah sebagai wakil negara harus terus didorong untuk peduli dan berani membangun kemauan kuat untuk membentuk lembaga dan payung regulasi layanan konseling di banyak bidang untuk keperluan yang semakin beragam khususnya penananganan dan pencegahan rasa trauma dari dampak peristiwa terorisme.
\end{abstract}

Kata Kunci: SRL, Trauma dampak Terorisme, Konseling Anakanak 


\section{Pendahuluan}

Systematic Literature Review (SLR-Tinjauan Pustaka Sistematis) merupakan metode literature review yang mengidentifikasi, menilai, dan menginterpretasi temuan-temuan pada suatu topik penelitian untuk menjawab pertanyaan penelitian (research question) yang telah ditetapkan sebelumnya (Kitchenham \& Charters, 2007). ${ }^{1}$ Metode tersebut dilakukan sistematis mengikuti tahapan dan protokol agar terhindar dari bias dan pemahaman subyektif. Biasanya SLR dilakukan peneliti bidang farmasi atau kedokteran, dan mulai dibawa ke dunia computing khususnya software engineering tahun 2007 oleh Barbara Kitchenham dalam makalah berjudul Guidelines in performing Systematic Literature Reviews in Software Engineering.

Metode SLR telah digunakan pada beberapa riset, salah satunya digunakan oleh Triandini, dkk (2019). ${ }^{2}$ Dijelaskan dalam publikasinya bahwa SLR dimanfaatkan untuk identifikasi, mengkaji, mengevaluasi, dan menafsirkan riset dengan bidang topik fenomenal, dengan pertanyaan riset tertentu yang relevan. Metode SLR dapat dilakukan review dan identifikasi artikel jurnal secara sistematis, yang setiap prosesnya mengikuti langkah dan protokol. Dalam publikasi di atas, metode SLR digunakan dalam riset teknologi informasi. Sementara itu, dalam artikel publikasi berbeda, Hariyati (2010), ${ }^{3}$ menjelaskan dalam publikasinya bahwa SLR merupakan metode yang menggunakan review, telaah, evaluasi terstruktur, pengklasifikasian, dan pengkategorian dari evidence based-evidence based yang telah dihasilkan sebelumnya. Menurut Hariyati, langkah dan strategi pelaksanaan SLR sangat terencana dan terstruktur sehingga sangat berbeda dengan metode yang hanya sekedar menyampaikan studi literatur. Dalam studinya, metode SLR digunakan pada riset keperawatan. Artikel ini menggunakan metode SLR untuk mengungkap dampak teror terhadap anak dan remaja di lokasi dan dampak tidak langsung teror yang disiarkan melalui media massa, serta bagaimana layanan konseling dan terapi trauma digunakan banyak negara dunia untuk mengatasi kesehatan jiwa pascateror. Selain itu, studi ini juga coba menemukan benang merah terhadap tindakan dan pelaksanaan konseling pascateror yang dilakukan di banyak negara seperti kebijakan yang melindungi korban teror, pembetukan badan khusus layanan konseling, dan rekrutmen

${ }^{1}$ Wahono, Romi Satria. (2015). "Systematic Literature Review: Pengantar, Tahapan dan Studi Kasus". Diunduh dari https://romisatriawahono.net/2016/05/15/systematic-literaturereview-pengantar-tahapan-dan-studi-kasus/ pada tanggal 20 Juni 2020 pukul 23.45

2 Triandini, dkk. (2019). "Metode Systematic Literature Review untuk Identifikasi Platform dan Metode Pengembangan Sistem Informasi di Indonesia". Indonesian Journal of Information Systems (IJIS) Vol. 1, No. 2, Februari 2019. Diunduh dari https://ojs.uajy.ac.id/index.php/IJIS/article/download/1916/1309 pada tanggal 20 Juni 2020 pukul 23.30 WIB

${ }^{3}$ Hariyati, RR. Tutik Sri. (2010). "Mengenal Systematic Review Theory dan Studi Kasus". Jurnal Keperawatan Indonesia. Vol 13, No 2 (2010). diunduh dari http://jki.ui.ac.id/index.php/jki/article/view/242 pada tanggal 21 Juni 2020 pukul 23.20 WIB 
sumber daya konselor yang tepat, serta merumuskan program konseling yang akurat dan efektif.

Kajian SLR artikel ini mengikuti tahapan yang dijelaskan Wahono (2015) yakni 1) planning, 2) conducting, 3) reporting. Planning meliputi Research Question (RQ) adalah bagian awal dan dasar berjalannya SLR. RQ digunakan untuk menuntun proses pencarian dan ekstraksi literatur. Analisis dan sintesis data, sebagai hasil dari SLR, adalah jawaban dari RQ yang kita tentukan di depan. RQ yang baik adalah yang bermanfaat, terukur, arahnya ke pemahaman terhadap state-of-the-art research dari suatu topik penelitian. Formulasi RQ harus didasarkan pada lima elemen yang terkenal dengan sebutan PICOC: 1) Population (P): Target group dari investigasi, 2) Intervention (I): Aspek detail dari investigasi, atau isu yang menarik bagi peneliti, 3) Comparison (C): Aspek dari investigasi dimana Intervention (I) akan dibandingkan, 4) Outcomes (O): Efek dan hasil dari Intervention (I), dan 5) Context (C): Setting dan lingkungan dari investigasi. Dengan meminjam Wahono (2015), kelima elemen dapat digambarkan dalam tabel berikut ini:

Tabel 1 Elemen PICOC

\begin{tabular}{|l|l|l|l|l|l|}
\hline Elemen & Jurnal 1 & Jurnal 2 & Jurnal 3 & Jurnal 4 & Jurnal 5 \\
\hline Population & $\ldots \ldots \ldots$ & $\ldots \ldots \ldots$ & $\ldots \ldots \ldots$ & $\ldots \ldots \ldots$ & $\ldots \ldots \ldots$ \\
\hline Intervention & $\ldots \ldots \ldots$ & $\ldots \ldots \ldots$ & $\ldots \ldots \ldots$ & $\ldots \ldots \ldots$ & $\ldots \ldots \ldots$ \\
\hline Comparison & $\ldots \ldots \ldots$ & $\ldots \ldots \ldots$ & $\ldots \ldots \ldots$ & $\ldots \ldots \ldots$ & $\ldots \ldots \ldots$ \\
\hline Outcomes & $\ldots \ldots \ldots$ & $\ldots \ldots \ldots$ & $\ldots \ldots \ldots$ & $\ldots \ldots \ldots$ & $\ldots \ldots \ldots$ \\
\hline Context & $\ldots \ldots \ldots$ & $\ldots \ldots \ldots$ & $\ldots \ldots \ldots$ & $\ldots \ldots \ldots$ \\
\hline
\end{tabular}

Langkah berikutnya penyusunan protokol yang berisi prosedur dan metode melakukan SLR biasanya memuat 7 elemen yakni: 1) Background, 2) Research Questions, 3) Search terms, 4) Selection criteria, 5) Quality checklist and procedures, 6) Data extraction strategy, dan 7) Data synthesis strategy. Meminjam pola Studies Selection Strategy yang dilakukan Wahono $(2015)^{5}$, dapat dijelaskan dalam bentuk bagan berikut ini:

Gambar 1 Pola Studies Selection Strategy yang dilakukan Wahono

$$
\begin{aligned}
& { }^{4} \mathrm{Ibid} \\
& { }^{5} \mathrm{Ibid}
\end{aligned}
$$




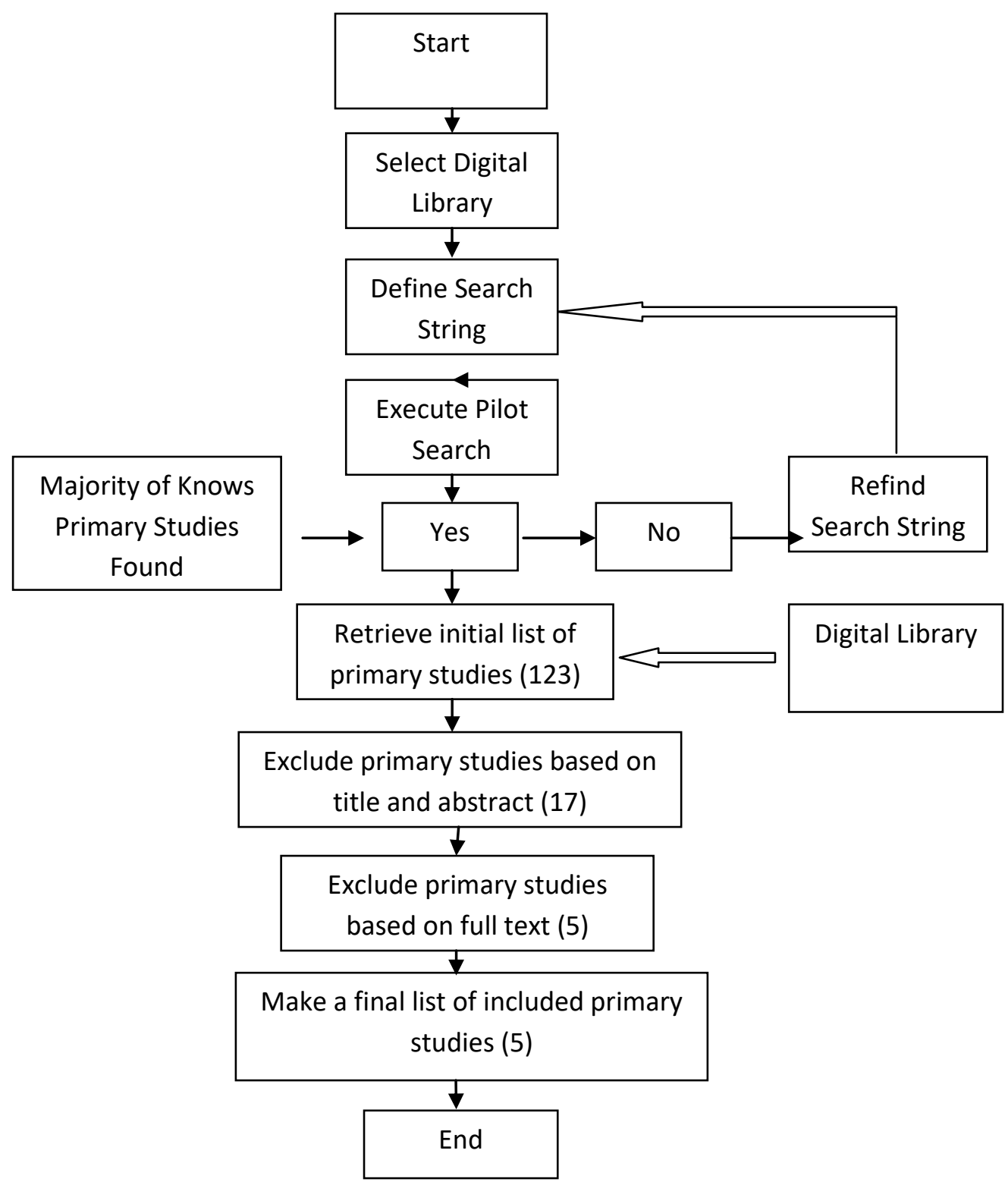

Berdasarkan langkah tersebut, ditemukan ratusan artikel yang terpublikasi melalui jurnal yang dilacak dan dipilih berdasarkan kata kunci "terrorism, children and adult" pada mesin pencari google, dilanjutkan pencermatan judul dan abstrak serta telaah kritis pada teks penuh (full text) artikel, selanjutnya dipilih 5 artikel dikaji dengan SLR. Pemilihan 5 artikel tersebut dapat dijelaskan dalam data berikut: 1) Publication Year: 2014-2016; 2) Publication Type: Journal; 3) Search String: Google Search Machine; 4) Selected Studies: 5 artikel. Setelah artikel didapatkan, langkah berikutnya memilih literatur yang sesuai untuk menjawab pertanyaan yang ingin dijawab yakni "bagaimana dampak terorisme terhadap anak dan remaja di lokasi teror dan dampak tidak 
langsung dari teror yang disiarkan media massa, serta bagaimana layanan konseling dan terapi trauma dibutuhkan oleh anak dan remaja untuk pulih menjadi lebih baik?" Untuk mempermudah proses tersebut dibuat kriteria sebagai filter pemilihan dan penolakan artikel (inclusion and exclusion criteria). Pemilihan dan penolakan artikel berdasarkan kriteria yang dijelaskan dalam tabel berikut ini:

Tabel 2 Selection Studies Wahono

\begin{tabular}{|l|l|}
\hline Inclusion Criteria & $\begin{array}{l}\text { Artikel ilmiah, terbit pada jurnal internasional, } \\
\text { terbit antara 2014-2016, memuat topik } \\
\text { terorisme dalam kaitannya dengan dampaknya } \\
\text { terhadap kesehatan mental dan kebutuhan } \\
\text { treatmen atau konseling pada klien terdampak. }\end{array}$ \\
\hline Exclusion Criteria & $\begin{array}{l}\text { Artikel kurang ilmiah, tidak terbit pada jurnal, } \\
\text { tidak terbit antara 2014-2016, memuat topik } \\
\text { terorisme tetapi tidak terkait dengan dampaknya } \\
\text { terhadap kesehatan mental dan kebutuhan } \\
\text { treatment atau konseling pada klien terdampak. }\end{array}$ \\
\hline
\end{tabular}

Metode SLR dapat digunakan untuk mereview dampak terorisme pada anak dan remaja dengan mengajukan beberapa pertanyaan: 1) bagaimanakah populasinya?, 2) bagiamanakah intervensinya?, 3) bagaimanakah perbandingannya, 4) bagaimanakah outcomes-nya, dan 5) bagaimanakah context-nya? Artikel ini mengkaji dan membahas 5 artikel jurnal terpilih berdasarkan tahapan yang dibuat secara obyektif untuk menemukan jawaban atas kelima pertanyaan di atas sekaligus coba merujuk pada kelima elemen PICOC SLR, yang kemudian diberikan rekomendasi bagaimanakah layanan konseling tepat masuk pada anak dan remaja dengan cengkeraman terorisme.

\section{Hasil dan Pembahasan}

Bagian pembahasan artikel ini merupakan tahapan conducting dalam kajian SLR terhadap artikel jurnal terpilih. Berdasarkan kajian dengan pendekatan SLR dapat disampaikan data dan analisis berikut ini.

\section{Penyajian Data}

Tabel 3 Penyajian Data Kajian SLR Artike Jurnal terpilih 


\begin{tabular}{|c|c|c|c|c|c|}
\hline Elemen & Jurnal $1^{6}$ & Jurnal $2^{7}$ & ${\text { Jurnal } 3^{8}}$ & Jurnal $4^{9}$ & Jurnal $5^{10}$ \\
\hline Population & Anak-anak & Anak-anak & $\begin{array}{l}\text { Anak dan } \\
\text { remaja }\end{array}$ & Anak-anak & $\begin{array}{l}\text { Anak- } \\
\text { Anak } \\
\text { Sekolah }\end{array}$ \\
\hline Intervention & $\begin{array}{l}\text { Pendekatan } \\
\text { inovatif } \\
\text { untuk } \\
\text { perencanaan } \\
\text { kesiapsiagaa } \\
\text { n }\end{array}$ & $\begin{array}{l}\text { Layanan } \\
\text { intervensi } \\
\text { dini }\end{array}$ & $\begin{array}{l}\text { Intervensi } \\
\text { konseling } \\
\text { untuk } \\
\text { trauma }\end{array}$ & $\begin{array}{l}\text { Inisiatif } \\
\text { kebijakan } \\
\text { dan respons } \\
\text { terprogram }\end{array}$ & $\begin{array}{l}\text { Layanan } \\
\text { kesehatan } \\
\text { mental }\end{array}$ \\
\hline Comparison & $\begin{array}{l}\text { Efek } \\
\text { serangan } \\
\text { teroris pada } \\
\text { kesehatan } \\
\text { psikologis } \\
\text { orang } \\
\text { mencakup } \\
\text { berbagai } \\
\text { macam } \\
\text { seperti gejala } \\
\text { stres akut } \\
\text { hingga } \\
\text { gangguan } \\
\text { jangka } \\
\text { panjang } \\
\text { seperti Post- }\end{array}$ & $\begin{array}{l}\text { Kekerasan } \\
\text { ekstrim dan } \\
\text { terorisme, } \\
\text { baik secara } \\
\text { langsung } \\
\text { dengan } \\
\text { menyaksikan } \\
\text { aksi atau } \\
\text { tidak langsung } \\
\text { dengan } \\
\text { menontonny } \\
\text { a di media, } \\
\text { memengaru } \\
\text { hi kesehatan } \\
\text { mental dan }\end{array}$ & $\begin{array}{l}\text { Para } \\
\text { profesional } \\
\text { konseling } \\
\text { mengataka } \\
\mathrm{n} \text { ancaman } \\
\text { traumatis } \\
\text { terhadap } \\
\text { anak-anak } \\
\text { tidak } \\
\text { ditemukan } \\
\text { dalam } \\
\text { peristiwa } \\
\text { besar atau } \\
\text { bahaya } \\
\text { orang } \\
\text { asing, } \\
\end{array}$ & $\begin{array}{l}\text { Efek } \\
\text { traumatis } \\
\text { sebagai } \\
\text { korban dan } \\
\text { efek tidak } \\
\text { langsung } \\
\text { sebagai } \\
\text { penduduk } \\
\text { yang tinggal } \\
\text { di } \\
\text { komunitas } \\
\text { dan } \\
\text { masyarakat } \\
\text { mana } \\
\text { ancaman } \\
\text { terorisme }\end{array}$ & $\begin{array}{l}\text { Persepsi } \\
\text { anak- } \\
\text { anak } \\
\text { Turki } \\
\text { Tentang } \\
\text { terorisme } \\
\text { lokal dan } \\
\text { global } \\
\text { yakni } \\
\text { sebagian } \\
\text { besar } \\
\text { anak } \\
\text { memiliki } \\
\text { pengetah } \\
\text { uan } \\
\text { tentang }\end{array}$ \\
\hline
\end{tabular}

${ }^{6}$ Karnik, Sameera S. \& Amar Kanekar. (2014). "The effects of terrorism on adult mental health: a public health preparedness approach". GLOBAL JOURNAL OF MEDICINE AND PUBLIC HEALTH. GJMEDPH 2014; Vol. 3, issue 3. Diunduh dari http://www.gjmedph.com/uploads/R4-Vo3No3.pdf pada tanggal 15 Juni 2020 pukul 23.30 WIB

${ }^{7}$ Leiner, Marie et.al. (2016). "Mental and Emotional Health of Children Exposed to News Media of Threats and Acts of Terrorism: The Cumulative and Pervasive Effects". Front Pediatr. v.4; 2016. Diunduh dari https://www.ncbi.nlm.nih.gov/pmc/articles/PMC4803729/ pada tanggal 16 Juni 2020 pukul 23.30 WIB

8 Meyers, Laurie. (2014). "The toll of childhood trauma". June 23, 2014. Diunduh dari https://ct.counseling.org/2014/06/the-toll-of-childhood-trauma/ pada tanggal 15 Juni 2020 pukul 23.45 WIB

${ }^{9}$ Garbarino, James, dkk. (2015). "Children and Terrorism”. Society for Research in Child Develepoment. Diunduh dari https://files.eric.ed.gov/fulltext/ED569207.pdf tanggal 20 Juni 2020 pukul 23.39 WIB

${ }^{10}$ Aricak, Tolga, dkk. (2015) “Turkish Elementary School Students' Perceptions of Local and Global Terrorism", Journal Education and Psychology. Diunduh dari https://www.redalyc.org/pdf/2931/293121940007.pdf pada tanggal 21 Juni 2020 pukul 23.59 WIB 


\begin{tabular}{|c|c|c|c|c|c|}
\hline & $\begin{array}{l}\text { traumatic } \\
\text { Stress } \\
\text { Disorder } \\
\text { (PTSD). }\end{array}$ & $\begin{array}{l}\text { emosi anak- } \\
\text { anak }\end{array}$ & $\begin{array}{l}\text { tetapi } \\
\text { dalam } \\
\text { kekerasan } \\
\text { kronis dan } \\
\text { sistemik } \\
\text { yang di } \\
\text { terjadi dekat } \\
\text { atau dengan } \\
\text { rumah, } \\
\text { termasuk } \\
\text { terorisme. }\end{array}$ & ada & $\begin{array}{l}\text { serangan } \\
\text { teroris di } \\
\text { Turki, } \\
\text { Amerika } \\
\text { Serikat } \\
\text { dan } \\
\text { dunia. }\end{array}$ \\
\hline Outcomes & $\begin{array}{l}\text { Perencanaan } \\
\text { kesiapsiagaa } \\
\mathrm{n} \text { kesehatan } \\
\text { masyarakat } \\
\text { telah } \\
\text { meningkatka } \\
\mathrm{n} \\
\text { infrastruktur } \\
\text { kesehatan } \\
\text { publik. }\end{array}$ & $\begin{array}{l}\text { Tindak } \\
\text { lanjut kasus } \\
\text { ekonomi, } \\
\text { budaya, } \\
\text { melek } \\
\text { kesehatan, } \\
\text { kemahiran } \\
\text { bahasa, dan } \\
\text { kesenjangan } \\
\text { pendidikan. } \\
\text { Konseling } \\
\text { tambahan } \\
\text { diperlukan } \\
\text { untuk } \\
\text { memberi } \\
\text { tahu } \\
\text { manfaat } \\
\text { terapi. }\end{array}$ & $\begin{array}{l}\text { Konselor } \\
\text { di sekolah, } \\
\text { lembaga } \\
\text { penampun } \\
\text { gan, klinik, } \\
\text { praktik } \\
\text { pribadi, } \\
\text { dan tempat } \\
\text { lain } \\
\text { bekerja } \\
\text { dengan } \\
\text { anak-anak } \\
\text { untuk } \\
\text { menghenti } \\
\text { kan siklus } \\
\text { kekerasan. }\end{array}$ & $\begin{array}{l}\text { Muncul } \\
\text { kesadaran } \\
\text { bahwa } \\
\text { konsekuensi } \\
\text { bukan hanya } \\
\text { psikologis, } \\
\text { tapi juga } \\
\text { filosofis dan } \\
\text { spiritual. } \\
\text { Dilanjutkan } \\
\text { kesadaran } \\
\text { tentang } \\
\text { Ancaman } \\
\text { terorisme. } \\
\text { Kesadaran } \\
\text { menjadi } \\
\text { dasar } \\
\text { bertindak } \\
\text { damai, } \\
\text { optimisme } \\
\text { dan } \\
\text { pemberdaya } \\
\text { an. } \\
\text { Tindakan } \\
\text { konstruktif } \\
\text { telah } \\
\text { memberdaya } \\
\text { kan anak- } \\
\text { anak } \\
\end{array}$ & $\begin{array}{l}\text { Keluarga } \\
\text { diminta } \\
\text { mencipta } \\
\text { kan } \\
\text { layanan } \\
\text { kesehatan } \\
\text { mental } \\
\text { yang } \\
\text { diarahkan } \\
\text { membant } \\
\text { u orang } \\
\text { mengatas } \\
\text { i } \\
\text { perasaan } \\
\text { setelah } \\
\text { serangan } \\
\text { teroris. }\end{array}$ \\
\hline Context & $\begin{array}{l}\text { Tingkat } \\
\text { federal, }\end{array}$ & Negara & Negara & $\begin{array}{l}\text { Negara } \\
\text { Australia }\end{array}$ & $\begin{array}{l}\text { Negara } \\
\text { Turki }\end{array}$ \\
\hline
\end{tabular}




\begin{tabular}{|l|l|l|l|l|l|}
\hline & $\begin{array}{l}\text { negara } \\
\text { bagian dan } \\
\text { lokal }\end{array}$ & & & & \\
\hline
\end{tabular}

\section{Analisis Data}

Berdasarkan tabel data di atas, metode SLR dapat digunakan untuk mengidentifikasi isu dampak terorisme dalam kaitannya dengan konseling dan treatment (terapi).

\section{a. Population}

Metode SLR dapat digunakan untuk melacak dengan kata kunci "children and terrorism" melalui mesin pencarian google dan memunculkan banyak artikel dengan topik yang menghubungkan anak dengan dampak terorisme terhadap mereka serta konseling yang dapat digunakan untuk memberdayakan serta menciptakan kesehatan mental pascaterorisme. Dengan metode SLR juga dapat mengidentifikasi bahwa anak-anak menjadi salah satu populasi penting dari peristiwa terorisme di banyak belahan dunia, baik sebagai korban langsung sebab tinggal di lokasi peristiwa, maupun anak-anak yang terdampak kekerasan visual dan audiovisual melalui tayangan terorisme. Berdasarkan metode SLR pula dapat ditemukan bahwa anak-anak terdampak langsung dan tidak langsung tersebut mengalami trauma yang tidak ringan sehingga membutuhkan kehadiran konseling untuk mengatasi rasa traumatis.

\section{b. Intervention}

Metode SLR yang telah digunakan dapat menemukan bahwa trauma yang disebabkan peristiwa terorisme telah ditangani melalui intervensi atau treatmen tertentu bukan saja untuk mengobati trauma yang telah terjadi tetapi juga sekaligus melalukan langkah pencegahan agar peristiwa tidak berulang kembali. Dari data yang tercantum di tabel dapat dianalisis bahwa intervention penanganan dan pencegahan dampak terorisme terhadap populasi dilakukan secara karitatif dan sekaligus merumuskan kebijakan membentuk lembaga dan menyiapkan perangkat regulasi pelaksanaan layanan konseling. Layanan konseling dan terapi tidak diserahkan "sukarela" kepada masyarakat, tetapi melalui kebijakan negara dan lembaga pemerintah untuk membentuk lembagalembaga tertentu, memberikan payung regulasi pelaksanaan layanan konseling dan terapi agar layanan dapat berjalan kondusif dan berkualitas. Hal itu menunjukkan keseriusan negara-negara tersebut dalam memandang trauma sebagai masalah kesehatan mental kritis dampak dari peristiwa terorisme.

\section{c. Comparasion}

Metode SLR telah digunakan untuk mengidentifikasi bahwa intervention diterapkan untuk penanganan dan pencegahan trauma akibat dampak peristiwa terorisme baik langsung maupun tidak langsung. Intervention dilakukan dengan 
mempertimbangkan bahwa terorisme secara langsung maupun tidak telah menciptakan trauma mendalam bagi populasi, bahkan bukan hanya bagi anakanak yang berada di lokasi peristiwa terorisme, tetapi juga anak-anak yang berada jauh dari lokasi peristiwa namun mendapatkan akses informasi tayangan maupun berita tentang peristiwa terorisme yang terus direproduksi sehingga menciptakan kekerasan informasi yang mendorong rasa trauma dahsyat pada anak-anak. Rasa trauma itu bahkan mudah muncul oleh peristiwa kekerasan kecil di sekitar mereka disebabkan dampak trauma peristiwa terorisme di dunia yang berbeda.

Berdasarkan kenyataan tersebut, intervensi yang dilakukan negara telah menjadi upaya nyata penanganan dan pencegahan dampak trauma sebagai sesuatu yang serius dilakukan, bukan sekadar basa-basi politik atau lips service namun menjadi agenda bersama dan political will yang kuat dari pemimpin beberapa negara di dunia. Pembentukan lembaga khusus dan payung regulasi untuk menangani rasa trauma dan payung regulasi bagi berjalannya layanan konseling dan terapi trauma dampak terorisme dapat berjalan aman, nyaman dan berkualitas.

\section{d. Outcomes}

Metode SLR berhasil mengidentifikasi bahwa intervensi negara yang serius membentuk lembaga dan payung regulasi penanganan dan pencegahan rasa trauma akibat dampak peristiwa terorisme telah memberikan dampak kuat bagi tumbuhnya kepercayaan, rasa hormat, kenyamanan dan keamanan populasi secara umum. Political will yang kuat dari pemerintah dalam penanangan dan pencegahan rasa trauma sebagai dampak terorisme turut meningkatkan gairah populasi untuk bersama-sama bangkit dan berperan aktif melalui lembaga pendidikan, lembaga sosial, lembaga konseling, bahkan lembaga keluarga untuk turut serta menangani dan mencegah rasa trauma sebagai dampak peristiwa terorisme.

Selain itu, kebijakan membentuk lembaga dan payung regulasi layanan konseling juga turut mendorong masyarakat sedia belajar, literasi terhadap bahaya terorisme, kekerasan terhadap anak, pentingnya mencegah trauma dengan cara apapun, serta penguatan budaya dan ekonomi populasi sebagai bagian penting untuk mensukseskan program respon tersebut. Secara bersamasama ada kesadaran dari populasi dengan pemerintah untuk mewujudkan program konstruktif demi pencegahan dampak destruktif dan negatif dari peristiwa terorisme khususnya terhadap anak-anak.

\section{e. Context}

Metode SLR di atas juga telah mampu mengidentifikasi data bahwa context penanganan rasa trauma sebagai dampak peristiwa terorisme ialah negara dalam beberapa pemaknaannya ialah lembaga pemerintahan di berbagai tingkatan pusat maupun daerah. Kehadiran pemerintah sebagai wakil negara 
untuk terjun langsung dalam penanganan dan pencegahan rasa trauma sebagai dampak peristiwa terorisme menjadi bukti bahwa masalah tersebut merupakan persoalan serius bagi mereka. Negara tidak ingin main-main dengan peristiwa merebaknya rasa trauma pada anak-anak sebab mereka generasi yang akan melanjutkan kehidupan dan kepemimpinan sebuah negara di masa mendatang, sehingga tumbuh kembang mereka dapat terganggu di bawah tekanan rasa trauma oleh peristiwa terorisme secara langsung maupun tidak langsung.

Berdasarkan data dan pembahasan di atas, SLR mampu mengungkap dampak terror terhadap anak dan remaja di lokasi teror dan dampak tidak langsung teror yang disiarkan melalui media massa di banyak negara di dunia. SLR juga telah mampu menunjukkan bahwa layanan konseling dan terapi trauma penting dilakukan untuk memulihkan korban teror menjadi lebih baik. Studi ini juga telah menemukan bahwa banyak negara telah bersikap tegas dan responsif pada anak dan remaja yang terkena dampak teror di lokasi maupun dampak tidak langsung yang disiarkan melalui media massa dengan cara merumuskan dan melaksanakan kebijakan pemerintah pusat dan daerah yang melindungi korban dari trauma. Selain itu, banyak negara juga telah mewujudkan layanan konseling dan terapi trauma untuk mengatasi masalah trauma pada anak dan remaja disebabkan dampak teror di lokasi dan dampak tidak langsung yang disiarkan oleh media massa. Studi yang dilakukan Kamik Samira dan Amar Kanikar (2014) ${ }^{11}$ menunjukkan dampak teror terhadap kesehatan mental manusia yakni trauma yang dapat mengubah kesehatan jiwa seseorang dan masyarakat. Dampak teror juga telah menyebabkan stress akut, perasaan takut, horor, ketidakberdayaa, penghindaran dari orang lain, kecemasan, menyendiri, resiko masa depan dan kesulitan menghadapi situasi hidup.

Melalui studi SLR terhadap artikel ilmiah dari beberapa negara menunjukkan keseriusan negara-negara di dunia dengan langsung hadir di tengah masyarakat melalui program nyata dan bersentuhan dengan persoalan di lapangan. Negara-negara di dunia tidak tinggal diam dan tidak menyerahkan masalah dampak teror secara langsung dan tidak langsung kepada masyarakat. Pemerintah pusat dan daerah di negara-negara dunia tidak main-main bersikap terhadap dampak jangka panjang dan jangka pendek dari trauma anak dan remaja yang dapat mempengaruhi kesehatan mental masyarakat. Paling nyata peran dan tindakan pemerintah negara-negara dunia ialah dengan cepat dan responsif menunjukkan rasa tanggung jawab mereka dengan cara membuat regulasi kebijakan yang dapat melindungi program penanganan dampak teror terhadap anak dan remaja. Pemerintah juga membentuk lembaga atau badan khusus melakukan layanan konseling dan terapi trauma untuk mengurangi atau menghilangkan trauma yang mengganggu kesehatan mental dalam jangka

${ }^{11}$ Karnik, Sameera S. \& Amar Kanekar. (2014). "The effects of terrorism on adult mental health: a public bealth preparedness approach". GLOBAL JOURNAL OF MEDICINE AND PUBLIC HEALTH. GJMEDPH 2014; Vol. 3, issue 3 
pendek dan jangka panjang. Layanan konseling dilaksanakan dengan dukungan dana, dukungan program dan dukungan sumber daya berkualitas untuk menjamin pelaksanaan konseling terhadap trauma anak dan remaja terdampak teror.

Hal itu selaras dengan tujuan konseling berangkat dari pengertiannya bahwa konseling merupakan bentuk pembelajaran yang intim dan menuntut seorang praktisi bersedia menjadi orang yang otentik dalam hubungan terapeutik ${ }^{12}$ (Corey, 2013). Dalam proses konseling, seorang konselor melakukan aktivitas konseling dalam upaya membantu klien terlibat dalam jenis perilaku yang mengarah penyelesaian masalah klien $^{13}$ (Krumboltz, 1965, p. 3 (dalam Flanagan, J.S 2015. Hal 8). Terkait penjelasan di atas, dalam konseling terdapat tiga komponen yang harus dihadirkan yakni konselor, konseli (klien) dan hubungan terapeutik (hubungan konseling). Konselor perlu melakukan segala cara terbaik untuk mendengarkan konseli (klien) dan bekerja bersamanya untuk memahami dan menyelesaikan masalah yang dihadapi. Konselor tidak mendiagnosa atau melabel seseorang, tetapi melakukan hal terbaik untuk bekerja dalam kerangka apapun untuk menemukan pemahaman paling masuk akal pada setiap konseli (klien). ${ }^{14}$ Sementara proses konseling yakni konselor efektif mengembangkan rencana konseling (terapi) bersama klien dengan cara menguraikan tujuan yang diinginkan bersama antara konselor dan klien. Setelah tujuan dirumuskan, konselor menarik benang merah dari upaya awal menggali informasi dan pengetahuan dari interaksi dengan klien untuk menafsirkan, refleksi, dan mendampingi klien mencapai tujuan terapeutik.

\section{Penutup}

Dari planning, conducting dan reporting di bagian pendahuluan dan pembahasan artikel, dapat disimpulkan bahwa terorisme telah memberikan dampak traumatis kepada banyak orang khususnya anak dan remaja. Dampak terorisme dapat dialami anak dan remaja pada mereka yang tinggal di lokasi kejadian teror serta anak dan remaja dari keluarga pelaku terror yang mengalami stigma negatif dari masyarakat sebagai kelaurga teroris. Anak dan remaja terdampak terorisme mengalami persoalan krusial untuk dapat bangkit dan menjalani perkembangan psikologisnya secara wajar dan tanpa tekanan trauma

12 Corey, Gerald. 2013. Theory and Practice of Counseling and Psychotherapy (9 th edition). California: Brooks / Cole. 2.

${ }^{13}$ Flanagan, J.S \& Flanagan, R.S. 2015. Counseling and Psychotherapy Theories in Context and Practice: Skills, Strategies and Techniques. New Jersey: John Wiley and Sons 3. (Krumboltz, 1965, p. 3 (dalam Flanagan, J.S 2015. Hal 8)

${ }^{14}$ McLeod, John. 2013. An Introduction to Counseling (5th edition). New York: Open University Press 
sehingga membutuhkan konseling tertentu agar mereka bangkit dan optimis memandang perjalanan hidup dan tahapan perkembangan mereka berikutnya.

Rekomendasi dari kajian ini ialah perlunya konseling mengambil peran strategi sebagai upaya membangun sikap positif anak dalam menghadapi tahapan hidup berikutnya agar mereka dapat menjalani dan mewujudkan perkembangan karir secara positif sebagaimana lazimnya anak dan remaja lain yang tidak terdampak terorisme. Terlebih lagi, belajar dari banyak negara, pemerintah sebagai wakil negara harus terus didorong untuk peduli dan berani membangun kemauan kuat untuk membentuk lembaga dan payung regulasi layanan konseling di banyak bidang untuk keperluan yang semakin beragam khususnya penananganan dan pencegahan rasa trauma dari dampak peristiwa terorisme.

\section{Daftar Pustaka}

Aricak, Tolga, dkk. (2015) “Turkish Elementary School Students' Perceptions of Local and Global Terrorism", Journal Education and Psychology. Diunduh dari https://www.redalyc.org/pdf/2931/293121940007.pdf pada tanggal 21 Juni 2020 pukul 23.59 WIB

Corey, Gerald. 2013. Theory and Practice of Counseling and Psychotherapy (9 th \edition). California: Brooks / Cole. 2.

Corey, Gerald.2009. The Art of Integrative Counseling, Second Edition. USA: Thompson brook

Flanagan, J.S \& Flanagan, R.S. 2015. Counseling and Psychotherapy Theories in Context and Practice: Skills, Strategies and Techniques. New Jersey: John Wiley and Sons 3. (Krumboltz, 1965, p. 3 (dalam Flanagan, J.S 2015. Hal 8)

Garbarino, James, dkk. (2015). "Children and Terrorism". Society for Research in Child Develepoment. Diunduh dari https://files.eric.ed.gov/fulltext/ED569207.pdf tanggal 20 Juni 2020 pukul 23.39 WIB

Karnik, Sameera S. \& Amar Kanekar. (2014). "The effects of terrorism on adult mental health: a public health preparedness approach". GLOBAL JOURNAL OF MEDICINE AND PUBLIC HEALTH. GJMEDPH 2014; Vol. 3, issue 3 . Diunduh dari http://www.gjmedph.com/uploads/R4-Vo3No3.pdf pada tanggal 15 Juni 2020 pukul 23.30 WIB

Leiner, Marie et.al. (2016). "Mental and Emotional Health of Children Exposed to News Media of Threats and Acts of Terrorism: The Cumulative and Pervasive Effects". Front Pediatr. v.4; 2016. Diunduh dari https://www.ncbi.nlm.nih.gov/pmc/articles/PMC4803729/ pada tanggal 16 Juni 2020 pukul 23.30 WIB 
McLeod, John. 2013. An Introduction to Counseling (5th edition). New York: Open University Press

Meyers, Laurie. (2014). "The toll of childhood trauma". June 23, 2014. Diunduh dari https://ct.counseling.org/2014/06/the-toll-of-childhood-trauma/ pada tanggal 15 Juni 2020 pukul 23.45 WIB

Triandini, dkk. (2019). "Metode Systematic Literature Review untuk Identifikasi Platform dan Metode Pengembangan Sistem Informasi di Indonesia". Indonesian Journal of Information Systems (IJIS) Vol. 1, No. 2, Februari 2019. Diunduh dari https://ojs.uajy.ac.id/index.php/IJIS/article/download/1916/1309 pada tanggal 20 Juni 2020 pukul 23.30 WIB

Wahono, Romi Satria. (2015). "Systematic Literature Review: Pengantar, Tahapan dan Studi Kasus". Diunduh dari https://romisatriawahono.net/2016/05/15/systematic-literaturereview-pengantar-tahapan-dan-studi-kasus/ pada tanggal 20 Juni 2020 pukul 23.45 